\title{
Environmental Estrogen
}

National Cancer Institute

\section{Source}

National Cancer Institute. Environmental Estrogen. NCI Thesaurus. Code C1894.

Environmental Estrogens are a variety of natural and synthetic substances that may mimic natural estrogen hormones. 